\title{
Simulation and life cycle assessment of process design alternatives for biodiesel production from waste vegetable oils
}

\author{
Sérgio Morais ${ }^{\mathrm{a}, \mathrm{b}, *}$, Teresa M. Mata ${ }^{\mathrm{a}}$, António A. Martins ${ }^{\mathrm{a}}$, Gilberto A. Pinto ${ }^{\mathrm{c}}$, Carlos A.V. Costa ${ }^{\mathrm{a}}$ \\ a Faculdade de Engenharia, Universidade do Porto, Rua Dr. Roberto Frias, 4200-465 Porto, Portugal \\ ${ }^{\mathrm{b}}$ REQUIMTE/Instituto Superior de Engenharia do Porto (ISEP), Rua Dr. António Bernardino de Almeida, 431 4200-072 Porto, Portugal \\ ${ }^{\mathrm{c}}$ Departamento de Engenharia Química, Instituto Superior de Engenharia do Porto (ISEP), Rua Dr. António Bernardino de Almeida, $4314200-072$ Porto, Portugal
}

\begin{abstract}
A B S T R A C T
This study uses the process simulator ASPEN Plus ${ }^{\circledR}$ and Life Cycle Assessment (LCA) to compare three process design alternatives for biodiesel production from waste vegetable oils that are: the conventional alkali-catalyzed process including a free fatty acids (FFAs) pre-treatment, the acid-catalyzed process, and the supercritical methanol process using propane as co-solvent. Results show that the supercritical methanol process using propane as co-solvent is the most environmentally favorable alternative. Its smaller steam consumption in comparison with the other process design alternatives leads to a lower contribution to the potential environmental impacts (P's). The acid-catalyzed process generally shows the highest PEIs, in particular due to the high energy requirements associated with methanol recovery operations.
\end{abstract}

\author{
Keywords: \\ Biodiesel \\ Waste vegetable oil \\ Process design \\ Process simulation \\ Life cycle assessment (LCA) \\ Alkali-catalyzed process \\ Acid-catalyzed process \\ Supercritical methanol process
}

\section{Introduction}

Some of the biodiesel advantages over petroleum diesel are extensively reported in literature \$heehan et al., 1998; Nas and Berktay, 2007; Ma and Hanna, 1999; Srivastava and Prasad, 2000; Fukuda et al., 2001; Dorado et al., 2003; Knothe et al., 2003; Beer et al., 2002; Utlu and Kocak, 200\$ Among others, it is derived from renewable resources, it is biodegradable and with a higher flash point $(423 \mathrm{~K})$ that makes it less volatile and safer during its transportation and handling. Moreover, biodiesel has a more favorable combustion emission prfile than diesel, such as lower emissions of carbon monoxide, particulate matter and unburned hydrocarbons.

The high costs and limited availability of biodiesel feedstocks are however critical issues in this industry. The costs of vegetable oils can be up to $75 \%$ of the total manufacturing cost, which makes biodiesel production costs approximately 1.5 times higher than

\footnotetext{
* Corresponding author. REQUIMTE/Instituto Superior de Engenharia do Porto (ISEP), Rua Dr. António Bernardino de Almeida, 431 4200-072 Porto, Portugal. Tel.: +351228340500; +351228321159.

E-mail address:sacm@isep.ipp.pt(S. Morais).
}

those of diesel (Haas et al., 2002; Phan and Phan, 2008 For this reason, the use of waste vegetable oils can be an effective way of reducing production costs since it is $z 3$ times cheaper than virgin vegetable oils (Phan and Phan, 2008). In addition, it helps solving the environmental problems associated with disposal of the waste vegetable oils.

The purpose of this study is to compare the potential environmental impacts of three process design alternatives for biodiesel production from waste vegetable oils, using process simulation and the life cycle assessment (LCA) methodology. The process design alternatives include: (1) the alkali-catalyzed process with free fatty acids (FFAs) pre-treatment, (2) the acid-catalyzed process, and (3) the supercritical methanol process using propane as co-solvent. These process design alternatives are simulated using the process simulator ASPEN Plus ${ }^{\circledR}$ in order to estimate the inventory data for the three process typologies, considering the same plant capacity and product purity requirements.

\section{Biodiesel production from waste vegetable oil}

The most common way to produce biodiesel is by transesterification, in which a catalyzed chemical reaction involving 
a vegetable oil or fat (mainly composed by triglycerides) and an alcohol, yields fatty acid alkyl esters (or biodiesel) and glycerol. Alcohols such as ethanol, methanol or butanol can be used and the resulting esters are named respectively, methyl, ethyl or butyl esters. Methanol is the alcohol most commonly used industrially due to its low-cost relatively to the other alcohols.

\subsection{Alkali-catalyzed process}

There are several routes to obtain biodiesel from lipidic feedstocks. The most widely used is the transestefication of triglycerides with low molecular weight alcohols in the presence of a homogeneous alkali-catalyst and operated in a batch mode. For this process an excess of methanol must be used in the presence of the alkali-catalyst to shift the reaction to a maximum yield of biodiesel product.Freedman et al. (1984)recommend a methanol to oil molar ratio of $6: 1$, at reaction temperature of about $333.15 \mathrm{~K}$ that is near the methanol boiling point.

The alkali-catalyzed transestefication reaction is very sensitive to the presence of free fatty acids (FFAs) and water in the lipidic feedstocks (Canakci, 2007). When an alkali catalyst is added to these feedstocks, the FFAs react with the catalyst to form soap and water. The soap formation not only consumes catalyst, but also causes emulsions to be formed, which make it dificult to further recover and purify biodiesel. In order to maximize the formation of methyl esters Freedman et al. (1984)recommend to use rfined vegetable oils with an FFA content lower than $0.5 \%(\mathrm{w} / \mathrm{w})$. Additionally, the presence of water may cause ester sapofication under alkaline conditions.Ma et al. (1998)reports that the water content of vegetable oils should be kept below $0.06 \%(w / w)$.

Impurities such as water and FFAs may hinder an effient use of waste vegetable oils and other crude oils or fats. Waste vegetable oils typically contain $27 \%$ of FFAs, while animal fats may contain $5 \%-30 \%$ of FFAs (Van Gerpen, 2005). In these cases an acid catalyst such as sulfuric acid can be used to esterify the FFAs to methyl esters. The triglycerides remain essentially unconverted to esters for low methanol to oil molar ratios and short reactor residence times. The acid-catalyzed estefication can be used as a pretreatment operation to convert FFAs to methyl esters, this way reducing the FFA content of crude oil Lepper and Friesenhagen, 1986). The pretreated oil can then be transestefied with an alkali-catalyst to convert triglycerides into methyl esters.

\subsection{Acid-catalyzed process}

The pre-treatment operation can be avoided by using the acid catalyst, such as sulfuric acid, for the transestefication reaction, being it less sensitive than the alkali-catalyzed transestefication to the presence of FFAs and providing high conversion rates, although much longer times and higher reaction temperatures are required (Canacki and Van Gerpen, 1999. Moreover, a higher methanol to oil molar ratio is needed to promote high equilibrium conversions of triglycerides to esters. For example,anacki and Van Gerpen (1999)reported a $98.7 \%$ conversion in $48 \mathrm{~h}$, at a methanol to oil molar ratio of $30: 1$, and a reaction temperature of $333.15 \mathrm{~K}$. Zhang et al. (2003a) and Zheng et al. (2006) reported a $97 \%$ conversion for a reaction time of $4 \mathrm{~h}$, at a methanol to oil molar ratio of $50: 1$ and $353.15 \mathrm{~K}$ of reaction temperature.

Although the acid-catalyzed transestefication reaction is a one-step process, it relies on a large excess of alcohol for which recover costs may determine the process feasibility. Some authors performed an economic analysis of this process, concluding that the acid-catalyzed transestefication provides higher revenues than the alkali-catalyzed process with an FFA pre-treatment (Zhang et al., 2003a, 2003b).

\subsection{Supercritical methanol process}

The transesterfication of triglycerides with supercritical methanol is also receiving much attention Kusdiana and Saka, 2001a, 2001b; Bunyakiat et al., 2006; Demisbras, 2002; Kiwjaroun et al., 2009) for biodiesel production, since it is a catalyst-free process with high reaction rates, making it possible to perform the reaction in just a few minutes (about 4 min)Kusdiana and Saka, 2001b. As other advantages this process is insensitive to the presence of impurities in the vegetable oil, such as water and FFAs, and the FFAs can be esterfied simultaneously with the transestefication of triglycerides. However as reported byKusdiana and Saka (2001a) this process requires a very high methanol to oil molar ratio of about $42: 1$ and a very high reaction temperature and pressure of $623.15 \mathrm{~K}$ and $43 \mathrm{MPa}$ respectively, as optimal reaction conditions.

Kiwjaroun et al. (2009)assessed the PEIs of the supercritical methanol process in comparison to the conventional alkali-catalyzed process, using process simulation. Results of their study showed that higher PE's are obtained for the supercritical methanol process (in nine of the assessed eleven impact categories) in comparison with the conventional alkali-catalyzed process with an FFA pre-treatment of crude oil. The required higher amount of methanol to perform the supercritical transestefication reaction and subsequently the energy expenditure in methanol recovery are the main reasons for these results.

Alternatively, Cao et al. (2005) proposed the supercritical methanol method, using propane as co-solvent, which decreases the reaction temperature and pressure, as well as the alcohol to oil molar ratio. This is explained since propane decreases the critical point of methanol allowing the supercritical reaction to be carried out under milder conditions than those reported by Kusdiana (Kusdiana and Saka, 2001). In this case, the optimal reaction conditions are a temperature of $553.15 \mathrm{~K}$, a pressure of $12.8 \mathrm{MPa}$, an alcohol to oil molar ratio of $24: 1$ and propane to oil molar ratio of 0.05: 1 . At these conditions $98 \%$ of oils are converted to biodiesel for a reaction time of $10 \mathrm{~min}$. This process was further assessed by Kasteren and Nisworo (2007)who performed an economic analysis, considering an industrial production of biodiesel from waste vegetable oil and claiming that it can compete with the existing alkali and acid-catalyzed processes.

\subsection{Heterogeneous catalyzed processes}

The use of enzymes as a biological catalyst has shown good tolerance for the free fatty acid level of the feedstockWatanabe et al., 2001), but the research efforts in biocatalysis applied to biodiesel production are largely still at the laboratory stage. The use of zeolites and metal catalysts allow for the use of feedstocks with high FFA content (Kiss et al., 2006), but also scientifi and technical barriers persist relatively to its industrial-scale application. Therefore, such processes are out of the scope of this study.

\section{Study goal and scope dfinition}

This study aims to perform an environmental evaluation of three process design alternatives for biodiesel production from waste vegetable oils, using process simulation and life cycle assessment (LCA).

The process design alternatives considered in this study include: the alkali-catalyzed process with an FFA pre-treatment (AICP), the acid-catalyzed process (AcCP) and the supercritical methanol process using propane as co-solvent (ScMP). These processes were simulated using the process simulator ASPEN Plus ${ }^{\circledR}$ and the potential environmental impacts (PES) were evaluated using the 
LCA methodology as described in EN ISO 14040International Standard Organization, 2006 and by Guinée (2002)

The functional unit selected for this study is the production of $1000 \mathrm{~kg}$ of biodiesel based on a process plant with a capacity of 3500 tonnes per year.

Some LCA considerations and assumptions for this study are the following:

- Material and energy inputs and outputs associated with biodiesel production processes are estimated based on their simulations using the process simulator ASPEN Plus ${ }^{\circledR}$

- Inventory data for energy and materials production, transportation and waste treatment are obtained from the Ecoinvent Database ${ }^{\circledR}$ assuming the European situation.

- Three biodiesel production process alternatives are considered to be placed in the same site or geographical location, allowing for the use of standardized transportation distances.

- The distances considered in this study for materials transportation from its production to consumption and also waste materials transportation from where they are generated to where they are treated, are standard transportation distances for Europe as reported in the Ecoinvent guidelines (Frischknecht et al., 2004.

- Environmental burdens are allocated based on ma\$sowrates of the valuable products process streams (biodiesel and glycerol).

- The contribution to PEls concerning the constructing of process equipments and units are not considered in the inventory analysis for this study.

- The PEPs evaluation in this study considers as life cycle impact assessment method the CML 2001 baseline version 2.04 (Guinée, 2002; CMD).

- Ten PEI categories are considered for evaluation in this study including: abiotic resources depletion, aciffication, eutrophication, global warming, ozone layer depletion, human toxicity, fresh water aquatic ecotoxicity, marine aquatic ecotoxicity, terrestrial ecotoxicity and photochemical oxidation.

- The PEI categories are normalized by dividing them by reference values obtained for Western Europe, in 1995, as reported in literature (Huijbregts et al., 2003), whereas the reference values were calculated by applying the same characterization factors of the CML 2001 baseline version 2.04.

- No weighting factors are considered in this study for the normalized PEI categories and therefore results are not aggregated in a single total PEI index.

\section{Process design and simulation}

In order to gather the process data needed for the inventory analysis, models of the three biodiesel production process alternatives were developed and simulated using ASPEN Plus ${ }^{\circledR}$. Process plants with production capacities of 3500 tonnes per year for biodiesel production (corresponding to 8500 operating hours per year) were designed to operate in a continuous mode.

Despite the possible differences between results obtained from a process simulator or from a real process operation, the software capabilities of a process simulator allows one to obtain reliable information about the process. Currently available process simulators already incorporate comprehensive thermodynamic packages, vast component libraries and advanced calculation techniques (Canacki and Van Gerpen, 1999; Zheng et al., 2006

In this study some thermodynamic properties not available in the component library of Aspen Plus ${ }^{\circledR}$ were estimated using this process simulator after providing it with the component molecular structure.
A combination of NRTL (Non-Random Two Liquid) and UNIQUAC (UNiversal QUAsiChemical) thermodynamic/activity models were used to predict the activity coffcients in the process simulations, due to the presence of highly polar componentszhang et al., 2003a, 2003b; Kiwjaroun et al., 2009

Some components not directly available in the process simulator were represented by similar components chosen from the available components database. This is the case of triglycerides that are represented by triolein $\left(\mathrm{C}_{57} \mathrm{H}_{104} \mathrm{O}_{6}\right)$, FFA's existent in the waste vegetable oil that are represented by oleic acid $\left(\mathrm{C}_{18} \mathrm{H}_{34} \mathrm{O}_{2}\right)$ and fatty acid methyl esters (FAME) that are represented by oleic acid methyl ester $\left(\mathrm{C}_{19} \mathrm{H}_{36} \mathrm{O}_{2}\right)$. Oleic acid is the major fatty acid present in triglycerides of rapeseed oil, canola oil, palm oil, and peanut oil (Canacki and Van Gerpen, 2003; Harding et al., 200)\% and, therefore, it is the major free fatty acid present in waste vegetable oils derived from those vegetable oil feedstocks, although this simplification may not be appropriate for other vegetable oils.

In the three process alternatives, product purities were fifmed to be $99.1 \%(\mathrm{w} / \mathrm{w})$ for biodiesel, higher than the European biodiesel standard (EN 14214) spediication for esters content $(96.5 \% \mathrm{w} / \mathrm{w})$, and $91.0 \%(\mathrm{w} / \mathrm{w})$ for crude glycerol.

Vacuum operation for the methanol recovery and products purification was applied to keep the temperature at suitably low levels because of the FAME and glycerol thermal decomposition temperatures ( $523 \mathrm{~K}$ for FAME and $423.15 \mathrm{~K}$ for glycerol). As observed byZhang et al. (2003a)the use of aflash unit in the AlCP and AcCP processes for both FAME and glycerol pufication could not achieve the desired high purity requirements as fined for products, greater than $90 \%(\mathrm{w} / \mathrm{w})$, therefore it was applied a multistage distillation step for both processes.

\subsection{Alkali-catalyzed process with FFA pre-treatment}

Fig. 1 shows the alkali-catalyzed process model, with FFA pretreatment, obtained using the process simulator ASPEN Plus ${ }^{\circledR}$. A waste vegetable oil streamflowrate of $428.50 \mathrm{~kg} / \mathrm{h}$ (stream 104) is pre-heated in a heat exchanger with the estefication reactor products (stream 106A) and fed to the estefication reactor (R-100) where the FFAs are converted to methyl esters. As proposed by Zhang et al. (2003a)it is assumed a $6 \%(w / w)$ of FFA content in the waste vegetable oil.

As reactant to perform esterfication, it is used a fresh methanol stream flowrate of $9.50 \mathrm{~kg} / \mathrm{h}$ (101) mixed together with a stream of recycled methanol (110) and the sulfuric acid catalyst (stream 103).

The esterification reaction is performed at a temperature of $343.15 \mathrm{~K}$, a pressure of $405.3 \mathrm{kPa}$, a methanol to oil molar ratio of $6: 1$ and with $5 \%(\mathrm{w} / \mathrm{w})$ of sulfuric acid catalyst in methanolepper and Friesenhagen, 1986; Zhang et al., 2003a; Harding et al., 200.7 For this reaction it is assumed a 95\% conversion of FFA in methyl esters (Zhang et al., 2003a).

The esterification products (stream 106A) are cooled to $333.15 \mathrm{~K}$, in a heat exchanger used to simultaneously preheat the oil feed, and then are sent to a glycerol washing column (X-100), where fresh glycerol is used (stream 108) to wash out sulfuric acid and water, through three theoretical washing stages.

The treated vegetable oil that leaves the glycerol washing column (X-100) from the top stream (107) still contains a $0.30 \%$ content of non-reacted FFA, which is acceptable to perform then the transesterfication reaction.

The remaining components, mainly glycerol, water and acid catalyst leave the glycerol washing column (X-100) in the bottom stream (109) and are then charged into a distillation column (T100 ) where most of the non-reacted methanol (stream 110) to be recycled is recovered and fed again to the estefication reactor (R-100). 


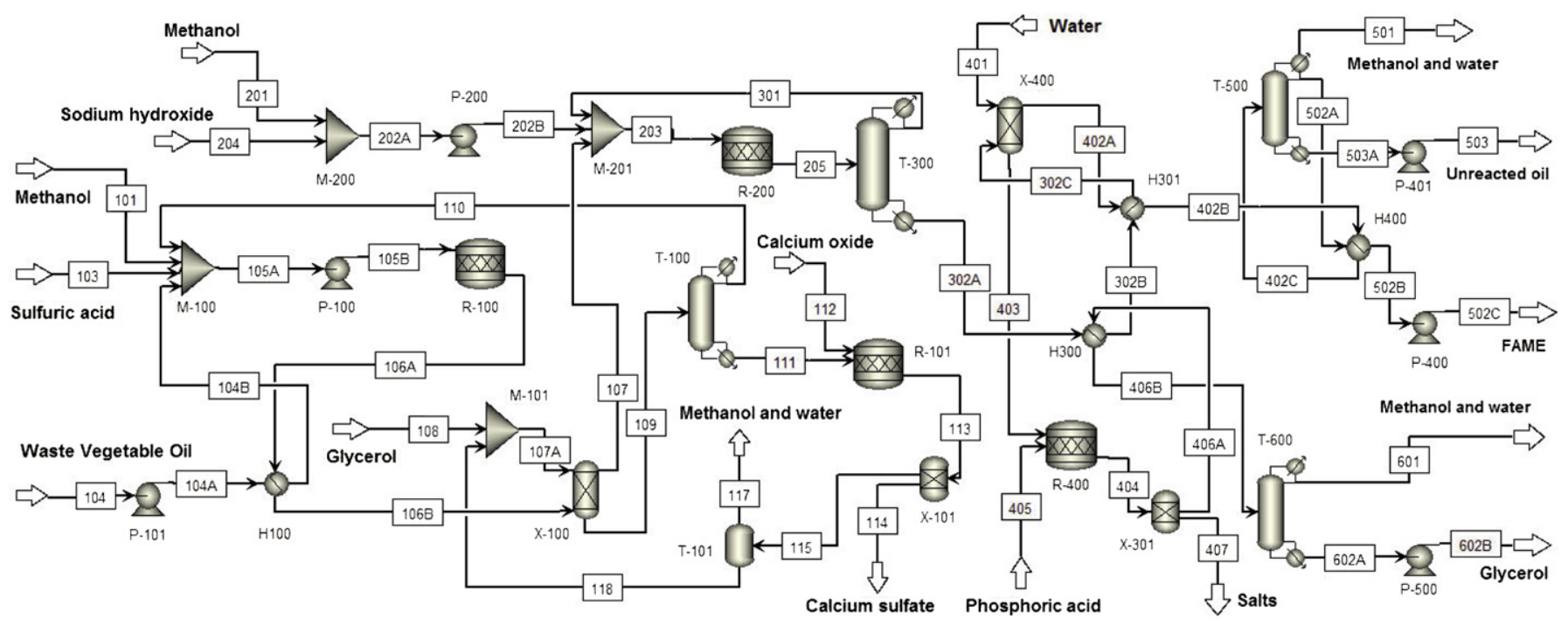

Fig. 1. Alkali-catalyzed process with FFA pre-treatment to produce biodiesel from waste vegetable oils.

Glycerol and sulfuric acid leave the distillation column (T-100) in the bottom stream (111), which is then fed to a neutralization reactor ( $\mathrm{R}-101)$ where sulfuric acid is removed from glycerol using calcium oxide (stream 112). The precipitated calcium sulfate is then removed in a gravity separator $(\mathrm{X}-101)$ and treated as a waste stream (114).

The glycerol stream (115) leaving the gravity separator (X-101) is then further purfied in a flash evaporator (T-101) where the remaining methanol and water are removed in the top stream (117) and treated as a waste stream due to its small mastlowrate of $6.97 \mathrm{~kg} / \mathrm{h}$. Theflash bottom stream (118) is then recycled back to the glycerol washing column (X-100) where it is mixed with a fresh glycerol stream (108).

The pretreated oil stream (107) resulting from the estefication process previously described, is then sent to the transestefication reactor (R-200), where a 6:1 molar ratio of methanol to oil is used with $1 \%(\mathrm{w} / \mathrm{w})$ of sodium hydroxide to perform the reaction (Freedman et al., 1984; Canacki and Van Gerpen, 1999; Harding et al., 2007). Transesterfication takes place at $333.15 \mathrm{~K}$ and $405.3 \mathrm{kPa}$ and reaches a 95\% conversion of oil to FAME, after $2 \mathrm{~h}$ (Zhang et al., 2003a; Kiwjaroun et al., 2009; Mancosky et al., 200.7

Before entering the transestefication reactor (R-200), a fresh methanol streamflowrate of $42.98 \mathrm{~kg} / \mathrm{h}$ is mixed with anhydrous sodium hydroxide. This last one is in solid state and thus, iffsakes need to befirst dissolved with methanol in a separated mixing unit.

The transesterfication reactor products (stream 205) are fed to a vacuum distillation column (T-300), where 94\% of methanol is recovered through four theoretical stages with a faux ratio of 1.5. The column top streamflowrate of $23.04 \mathrm{~kg} / \mathrm{h}$ of recovered methanol (301) is recycled back to the transestefication reactor, where it is mixed with a fresh methanol stream.

The column bottom stream (302A) mainly containing biodiesel and glycerol, is charged to a washing column (X-400), where water is used to wash biodiesel, providing separation of methanol, soap, glycerol and catalyst from FAME.

The top stream leaving the washing column (402A), mainly containing methyl esters and unconverted oil, is then feed to a vacuum distillation column (T-500), with six theoretical stages and operating at a relux ration of 1.5 to separate the remaining methanol and water from FAME and non-reacted oil.

In order to separate FAME from water and methanol, a partial condenser is used in the distillation column (T-500) overhead. FAME is obtained in the bottom stream (502A) of the column overhead condenser, with a mas\$lowrate of $411.13 \mathrm{~kg} / \mathrm{h}$ and $99.10 \%$ of purity. Water and methanol is obtained in the same condenser top stream (501) and have a small masflowrate of $1.77 \mathrm{~kg} / \mathrm{h}$ that is treated as waste. Unconverted oil is obtained in the column bottom stream (503) with a massflowrate of $22.44 \mathrm{~kg} / \mathrm{h}$. Although it is not considered in this study, this oil stream can be considered for further recycling and conversion within this process.

The bottom stream containing glycerol (403) that leaves the washing column (X-400) is then fed to a neutralization reactor ( $\mathrm{R}$ 400 ) in order to remove the catalyst. Hence, phosphoric acid is added in equivalent moles to the $\mathrm{NaOH}$ present in the stream. The resulting salts $\left(\mathrm{Na}_{3} \mathrm{PO}_{4}\right)$ are then removed in a gravity separator $(\mathrm{X}$ 301) and treated as waste.

Glycerol resulting from the neutralization reactor $(\mathrm{R}-400)$ is further purfied in distillation column (T-600) with three theoretical stages and operating at a reflx ration of 1.5. A small water and methanol flowrate of $7.79 \mathrm{~kg} / \mathrm{h}$ is removed in the column top stream (601) and treated as waste. At the column bottom stream (602A), a glycerol by-productflowrate of $43.73 \mathrm{~kg} / \mathrm{h}$ is obtained with $91 \%$ purity.

\subsection{Acid-catalyzed process}

The acid-catalyzed process for biodiesel production from waste vegetable oils is presented inFig. 2 .

In this process, a fresh methanol stream (102B) and a recycled methanol stream (201), of respectively $87.00 \mathrm{~kg} / \mathrm{h}$ and $60.48 \mathrm{~kg} / \mathrm{h}$, are mixed with sulfuric acid catalyst (stream 103) and a waste vegetable oil streamflowrate of $420.00 \mathrm{~kg} / \mathrm{h}(101 \mathrm{~A})$ and fed to the transesterification reactor (R-100). Reaction takes place at $353.15 \mathrm{~K}$ and at a pressure of $405.3 \mathrm{kPa}$, with waste oil to methanol and to acid molar ratios of $1: 50: 1.3$. At these conditions a $97 \%$ conversion of oils to FAME is achieved after 4 hZheng et al., 2006).

The transesterfication products (stream 106) are then fed to a distillation column (T-200) in order to separate the excess methanol, through four theoretical stages and a fax ratio of 2 . A methanol massflowrate of $670 \mathrm{~kg} / \mathrm{h}$ is obtained in the top column stream (201), corresponding to a $94 \%$ mass recovery, which is then recycled back to the transestefication reactor.

The bottom column stream (202) containing FAME, glycerol, non-reacted oil and the acid catalyst is fed to a neutralization reactor (R-200), where sulfuric acid is removed with calcium oxide. Equivalent moles of calcium oxide to the sulfuric acid are added, 


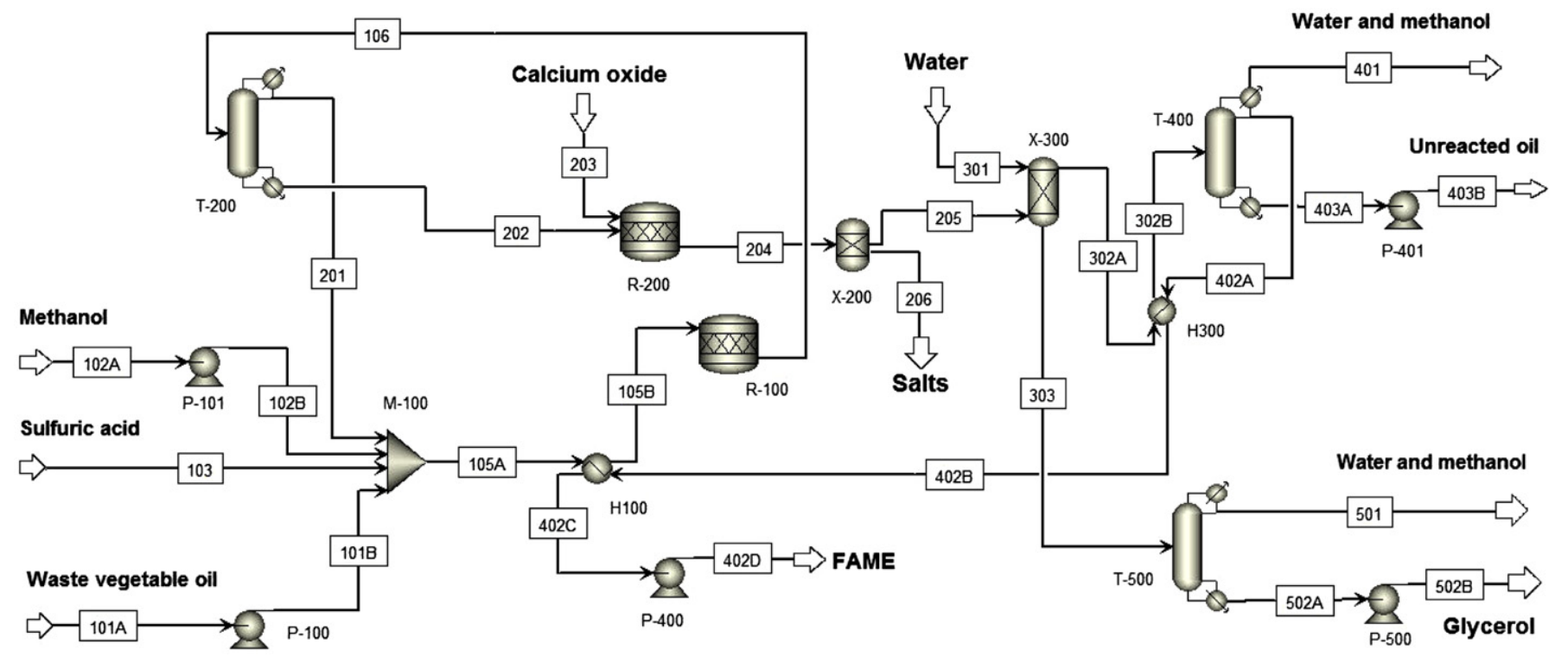

Fig. 2. Acid-catalyzed process for biodiesel production from waste vegetable oils.

producing calcium sulfate and water. Calcium oxide is used due to its low-cost relatively to other alkali substancesc(anacki and Van Gerpen, 1999). The salts are then removed in a gravity separator (X-200) and treated as waste.

The remaining water washing column (X-300) and biodiesel and glycerol purfication units (T-400 and T-500) are similar to the alkalicatalyzed process in terms of equipment sizing and operating conditions. FAME is obtained in the bottom stream (402A) of the column overhead condenser, having a massflowrate of $408.67 \mathrm{~kg} / \mathrm{h}$ and $99.14 \%$ of purity. The glycerol by-product is obtained in the column T500 bottom stream with aflowrate of $46.57 \mathrm{~kg} / \mathrm{h}$ and $91 \%$ purity.

\subsection{Supercritical methanol process using propane as co-solvent}

The supercritical methanol process for biodiesel production from waste vegetable oils is presented iffig. 3 .

In this process, $410 \mathrm{~kg} / \mathrm{h}$ of waste vegetable oil (stream 101A) is mixed with $45.33 \mathrm{~kg} / \mathrm{h}$ of fresh methanol (stream $102 \mathrm{~A}$ ), $297.5 \mathrm{~kg} / \mathrm{h}$ of recycled methanol (stream 202B) and propane (stream 102) and fed to the transesterfication reactor (R-100). Reaction takes place at $553.15 \mathrm{~K}$ a pressure of $12.7 \mathrm{MPa}$, an oil to methanol molar ratio of 1:24 and a methanol to propane molar ratio of 1:0.05(ao et al., 2005).

In order to model the supercritical methanol reaction conditions as accurately as possible, kinetic parameters (heat of reaction, activation energy and the pre-exponential factor from the Arrhenius equation) were used in the simulations. The reaction kinetics are given by Kasteren and Nisworo (2007)and are described in Table 1.

Within this reaction conditions conversion is almost complete after a residence time of $12.6 \mathrm{~min}$, in a pluglow reactor with $10 \mathrm{~cm}$ diameter and $7 \mathrm{~m}$ length.

The reaction products (stream 105) are fed tølash evaporator (X-200) where pressure is decreased to $506.6 \mathrm{kPa}$. This pressure drop has as result the transfer of liquid methanol and propane to the gaseous form. Theflash gas stream (201) is then recycled back to the reactor, since it contains $92.2 \%$ of methanol and $7.5 \%$ of propane at aflowrate of $279.93 \mathrm{~kg} / \mathrm{h}$. The bottonflash stream $203 \mathrm{~A}$ is sent to settler unit (X-201) to separate FAME (stream 204A) from the remaining methanol and glycerol (stream 205A).

In order to further purify methyl esters (stream 204A) by removing the remaining methanol and propane flash evaporator
(X-300) is used, where a FAME product (stream 302Bflowrate of $412.69 \mathrm{~kg} / \mathrm{h}$ is obtained with $99.15 \%$ purity.

The glycerol by-product (stream 205A) is also puffied in a flash evaporator (X-400) resulting in a glycerolflash bottom stream flowrate of $42.90 \mathrm{~kg} / \mathrm{h}$ with $91 \%$ purity and a methanol and propane flash top stream (401) that is recycled back to the transesterification reactor.

\section{Inventory analysis}

The data needed for the inventory analysis of this study is obtained after developing the three procestlowsheet models and performing their simulations.Table 2 shows the material and energy inputs and outputs per functional unit (i.e. per $1000 \mathrm{~kg}$ of biodiesel), for each of the three process alternatives analyzed: alkali-catalyzed process with FFA pre-treatment (AlCP), acid-catalyzed process (AcCP) and supercritical methanol process using propane as co-solvent (ScMP).

As shown in Table 2, the higher methanol to oil molar ratio for the acid-catalyzed transestefication reaction, relatively to the other process alternatives, led to a higher methanoflowrate of $670 \mathrm{~kg} / \mathrm{h}$ in the recycle loop $(23 \mathrm{~kg} / \mathrm{h}$ for AlCP and $297.5 \mathrm{~kg} / \mathrm{h}$ for ScMP). Therefore, a higher consumption of steam is shown in the $\mathrm{AcCP}$ and it is particularly due to the intensive steam requirements in the methanol recovery process. Moreover, due to the high catalyst mass flowrate in the acid-catalyzed transestefication reaction and consequently the need for its downstream neutralization and removal, originates a higher amount of solid wastes in comparison to the other alternatives.

The absence of catalyst in the supercritical methanol process greatly simplfies biodiesel purfication steps and therefore reduces the generation of wastes.

Although the potential environmental impacts related to equipment construction were not considered in this study scope one may see clear differences among the three process design alternatives. The simulator models for the three process alternatives show for the ScMP 12 main process units, for the AcCP 14 units and for the AlCP process 24 units. Moreover, the reactor residence time to perform the transestefication reaction in each of the three process design alternatives is sigrficantly different, leading to different reactor sizes. 


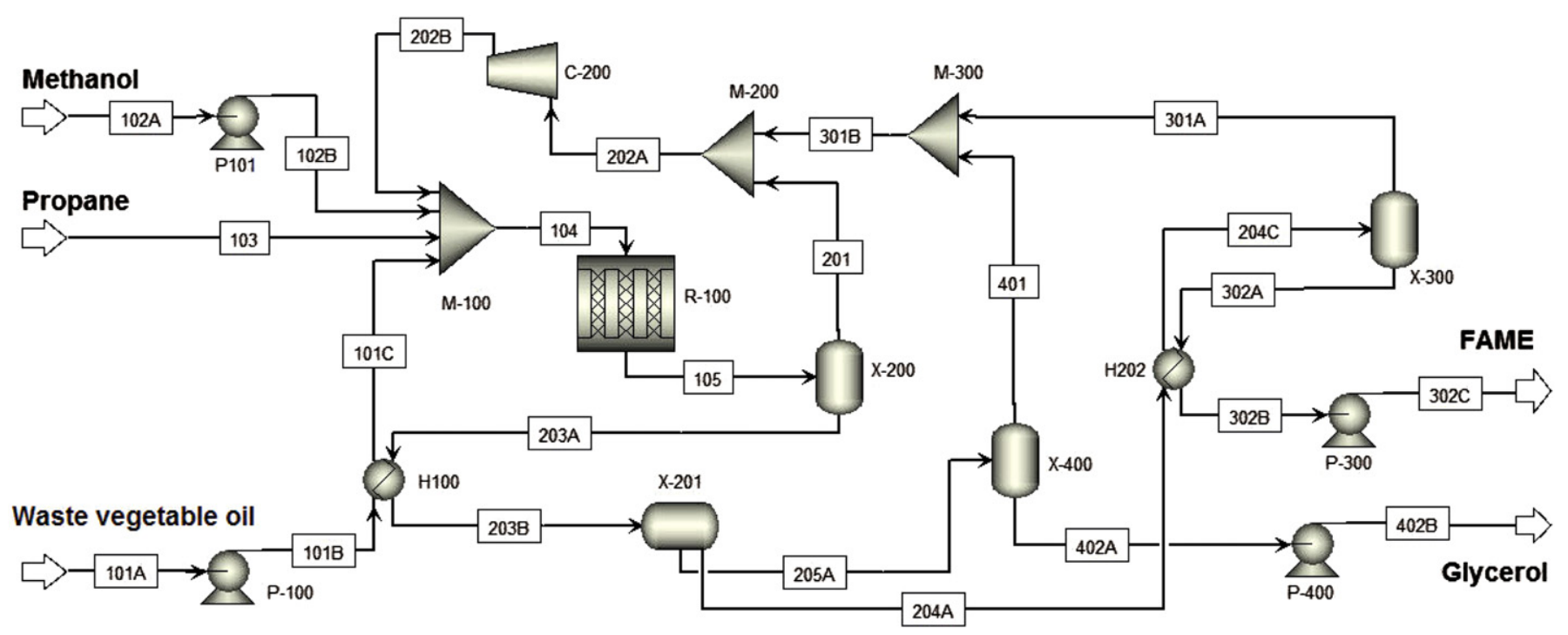

Fig. 3. Supercritical methanol process with propane as co-solvent to produce biodiesel from waste vegetable oils.

\section{Potential environmental impact assessment}

Fig. 4 shows the normalized potential environmental impacts of the conventional alkali- catalyzed process with FFA pre-treatment (AlCP). Marine aquatic ecotoxicity is the most sigficant impact category followed by abiotic resources depletion.

In the AlCP process alternative, steam use is the major contributor to almost all the PEI categories. Methanol recovery in both the pre-treatment step and in the downstream transesterification reaction and FAME puffication in the multi-stage distillation unit are the most energy intensive process units. Therefore, these are critical aspects to consider from an environmental standpoint.

Fig. 5 shows the normalized PEI categories for AcCP. Similarly to the alkaline catalyzed process, marine aquatic ecotoxicity is the most significant impact category followed by abiotic resources depletion. The use of low pressure steam, mainly in the methanol recovery distillation column, has a sigficant contribution to all the PEI categories.

Fig. 6 shows the normalized PEb associated with the ScMP. In this process alternative depletion of abiotic resources is the most significant impact category, mainly due to methanol use. Marine aquatic ecotocixity is the second largest impact category, mainly due to steam use.

Comparing the three process design alternatives, methanol use has a significant contribution to abiotic resources depletion since it is produced in a refinery based on fossil oil. The remaining resources needed for these processes, along with the waste treatment operations, is of secondary importance in terms of their contribution to the PEIs.

Fig. 7 shows the comparison among the normalized PEI categories of the three process design alternatives. Marine aquatic

\section{Table 1}

Kinetic parameters of Arrhenius equation used in the simulations of supercritical methanol reaction.

\begin{tabular}{lll}
\hline Kinetic parameter & Unit & Value \\
\hline Activation energy & $\mathrm{kJ} / \mathrm{kmol}$ & 38482 \\
Heat of reaction & $\mathrm{kJ} / \mathrm{s}$ & 0.032 \\
Reaction kinetics constant & $\mathrm{s}^{-1}$ & $7 \times 10^{-3}$ \\
\hline
\end{tabular}

ecotoxicity and abiotic resources depletion are the two most significant PEI categories for the three process alternatives. The PEI categories with a relatively low importance include: eutrophication, ozone layer depletion, human toxicity, fresh water aquatic ecotoxicity and photochemical oxidation.

The AcCP represents, relatively to the AlCP, an increase of $62 \%$ in abiotic resources depletion, $126 \%$ in acification (mainly due to the use of a large amount of sulfuric acid and a low pressure steam), $67 \%$ in global warming and $33 \%$ in marine aquatic ecotoxicity.

For the acid-catalyzed transestefication reaction, the use of a higher methanol to oil molar ratio, of 50:1, contributes to the higher energy requirements associated with methanol recovery. This is the main reason for the differences observed between the contributions of the three process alternatives to the PEIs. Also, this aspect of the acid-catalyzed process far outweighs the PIsIassociated with the FFA pre-treatment in the alkali-catalyzed process alternative.

Table 2

Material and energy inventory data for the three process alternatives.

\begin{tabular}{|c|c|c|c|}
\hline Inventory & $\mathrm{AlCP}$ & $\mathrm{AcCP}$ & ScMP \\
\hline \multicolumn{4}{|l|}{ Products } \\
\hline Biodiesel (kg) & 1000.00 & 1000.00 & 1000.00 \\
\hline Glycerol (kg) & 106.37 & 114.80 & 105.62 \\
\hline \multicolumn{4}{|l|}{ Feed } \\
\hline Waste vegetable oil (kg) & 1042.25 & 1035.32 & 995.51 \\
\hline Methanol (kg) & 126.80 & 214.45 & 110.09 \\
\hline $\mathrm{NaOH}(\mathrm{kg})$ & 9.80 & - & - \\
\hline $\mathrm{H}_{2} \mathrm{SO}_{4}(\mathrm{~kg})$ & 0.15 & 149.09 & - \\
\hline $\mathrm{H}_{3} \mathrm{PO}_{4}(\mathrm{~kg})$ & 7.95 & - & - \\
\hline $\mathrm{CaO}(\mathrm{kg})$ & 0.10 & 85.24 & - \\
\hline Propane (kg) & - & - & 0.02 \\
\hline Glycerol (kg) & 0.05 & - & - \\
\hline High pressure steam $\left(300^{\circ} \mathrm{C}\right)(\mathrm{kg})$ & - & - & 196.55 \\
\hline Medium pressure steam $\left(250^{\circ} \mathrm{C}\right)(\mathrm{kg})$ & 935.30 & 933.24 & 239.53 \\
\hline Low pressure steam $\left(100^{\circ} \mathrm{C}\right)(\mathrm{kg})$ & 1750.81 & 3366.96 & - \\
\hline Electricity (kWh) & 1.01 & 0.95 & 4.01 \\
\hline Water (Process) (kg) & 48.65 & 39.44 & - \\
\hline Water (Cooling) (kg) & 3143 & 5031 & 510 \\
\hline \multicolumn{4}{|l|}{ Waste } \\
\hline Salts (kg) (to landfill) & 16.00 & 205.71 & - \\
\hline $\begin{array}{l}\text { Hazardous liquid waste }(\mathrm{kg}) \\
\quad \text { (to wastewater treatment }\end{array}$ & 37.92 & 172.21 & - \\
\hline
\end{tabular}




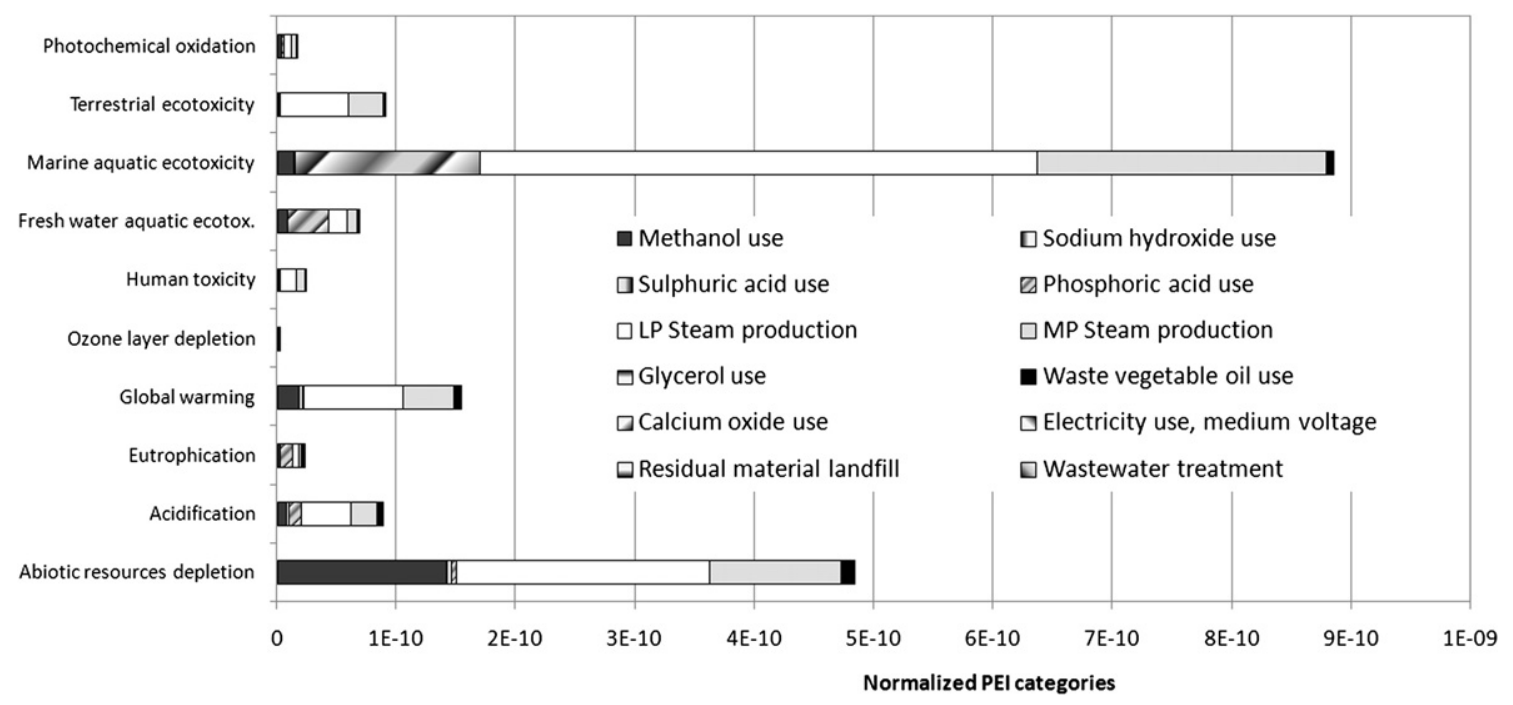

Fig. 4. Contribution of resources use and waste treatment to the normalized PEI categories of the alkali-catalyzed process with FFA pre-treatment.

The ScMP is the one with the least contribution to the P\$s which makes it the most environmentally favorable process design alterative for biodiesel production. In comparison with the AICP, the ScMP reduces abiotic resources depletion by $313 \%$, acification by $754 \%$, global warming by $496 \%$ and marine aquatic ecotoxicity by 793\%. It should be noted that the intended conclusions can be drawn without the need of a total PEI index, avoiding the inherent subjectivity of a weighting procedure.

The overall decrease in steam consumption associated with the ScMP in comparison with AICP and AcCP, is of fundamental importance to the observed differences. Also, the downstream operations associated with the supercritical methanol process are simpler than for the other process alternatives. This is explained because no catalyst is used, methanol is recovered just by decreasing pressure in aflash evaporator and glycerol is separated from FAME and further purfied in simpleflash evaporators for both product streams with substantial energy savings. Noteworthy is the comparison of these results with the outcome of the study undertaken by Kiwjaroun et al. (2009) in which the supercritical methanol process showed higher PEI than the conventional alkalicatalyzed process with an FFA pre-treatment, due to the required higher amount of methanol to perform the supercritical transesterification reaction and subsequently the energy expenditure in methanol recovery. The use of a co-solvent in the ScMP still have the advantage of avoiding waste production, but at lower temperature and methanol to oil molar ratios reaction conditions, enabling a better environmental performance relatively to the conventional AlCP. Additionally,Kiwjaroun et al. (2009)used an energy intensive multi-stage distillation process to separate glycerol from biodiesel in the supercritical methanol process (instead for example of using a simpler flash unit or a settler unit), which can be explained since it may be the only way of obtaining the desired high purity requirement for FAME (99.54\%), although a lower purity was obtained in the alkali-catalyzed process (99.10\%).

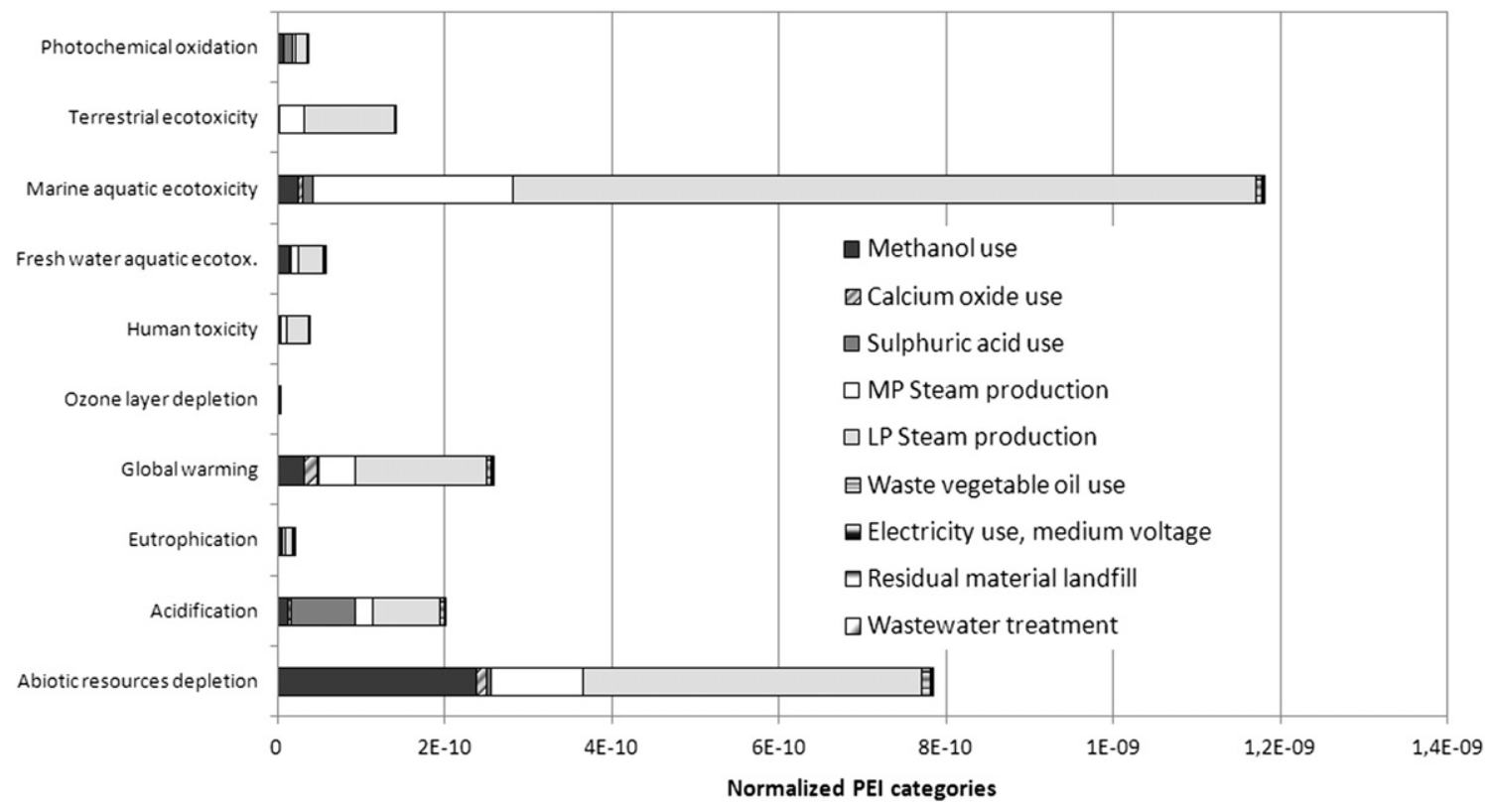

Fig. 5. Contribution of resources use and waste treatment to the normalized PEI categories of the acid-catalyzed process. 


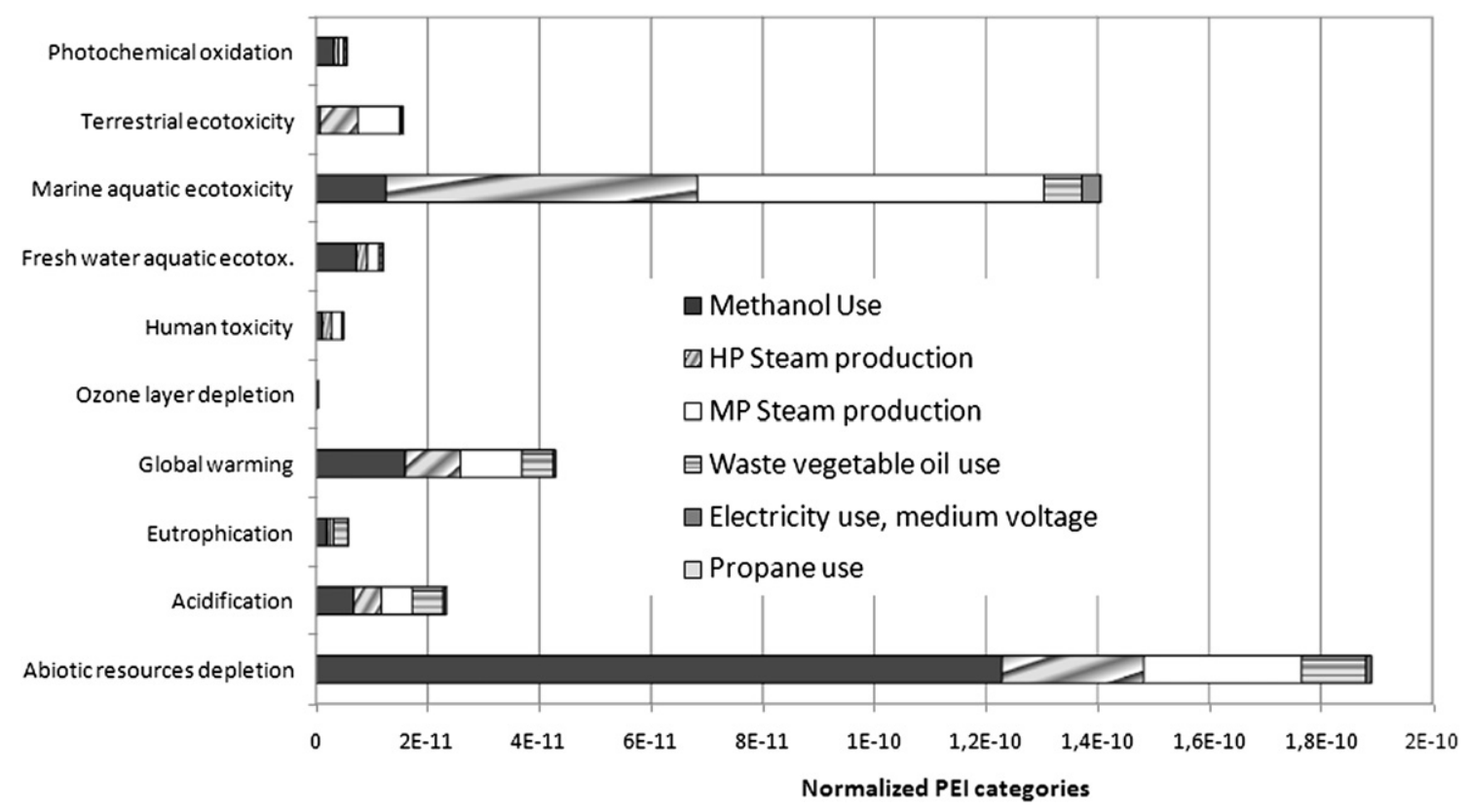

Fig. 6. Contribution of resources use to the normalized PEI categories of the supercritical methanol process using propane as co-solvent.

A larger scale production may make economically viable the further recovery and purfication of methanol and unconverted oil waste streams in both the alkali and acid-catalyzed processes. However in this study the impacts associated with waste management and treatment operations are of secondary importance. Also, any possible savings of methanol and unconverted oil from these waste streams are not expected to produce any sigficant change in the comparison results of the three process alternatives.

In the present study it is assumed that steam is produced using fossil fuels (natural gas and heavy fuel oil). Since steam use has a major contribution to the PEs of the three process design alternatives, it would be interesting to evaluate as a future work the potential environmental benefis of using by-product glycerol as fuel, at least in order to reduce depletion of abiotic resources. This assessment is especially relevant because of the expected increase of the worldwide production of biodiesel, which should contribute to an oversupply of glycerol which will decrease its market value or even becoming a waste product.

Other process alternatives may be environmentally and economically interesting, such as the application of a hydrodynamic cavitation reactor in the alkali-catalyzed process in order to minimize mass transfer resistance during the transestefiication reaction. It is claimed that this alternative, with a much lower reaction time, can lead to less saponfication or emulsfication, allowing the use a variety of feedstocks with broader range of free fatty acid concentrations, avoiding the FFA pre-treatment(Mancosky et al., 2007.) Moreover, the use of a co-solvent in the alkali-catalyzed process, such as tetrahydrofuran or methyl tertiary butyl ether, also minimizes the reaction mass transfer resistance decreasing the reaction time to $7 \mathrm{~min}$ and enabling the conversion of FFA into methyl ester\$Boocock et al., 1998). As future work, these process alternatives should be further assessed and compared with the results of the present study.

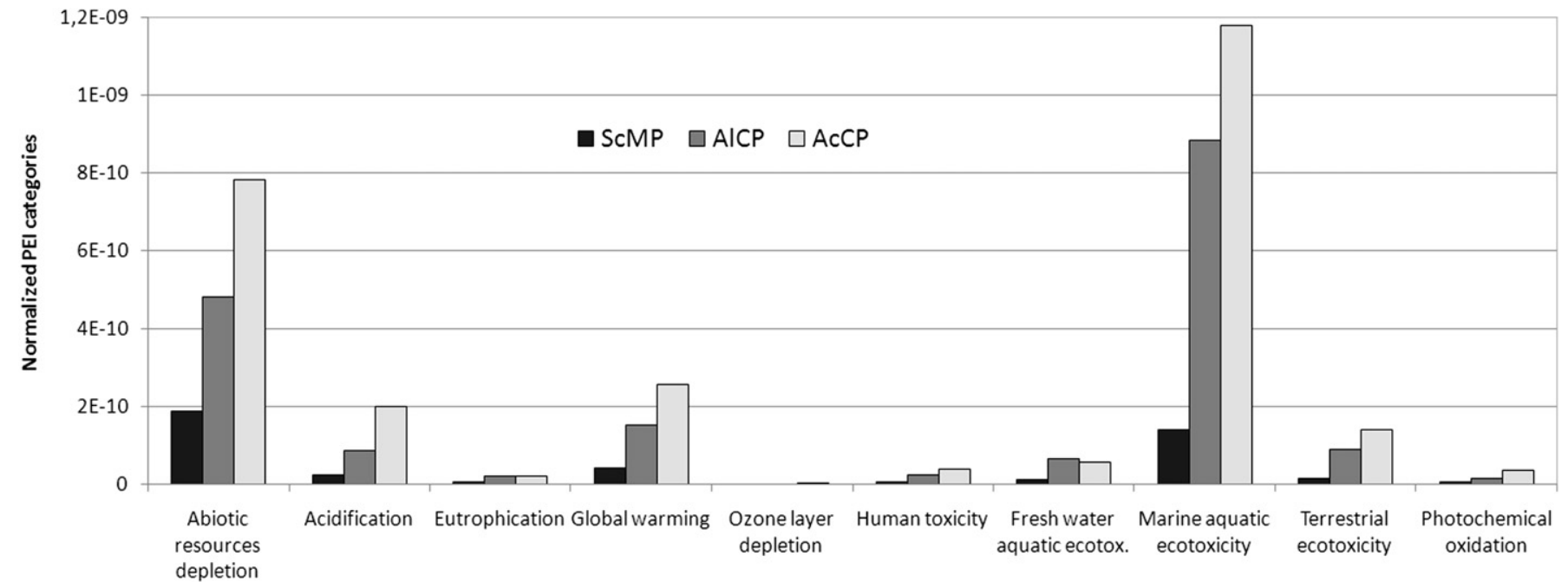

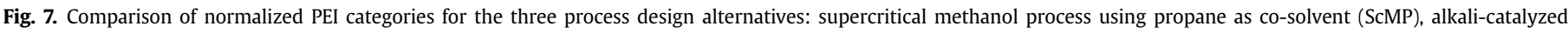
process with FFA pre-treatment (AlCP) and acid-catalyzed process (AcCP). 


\section{Conclusions}

For the three process alternatives analyzed, marine aquatic ecotoxicity and depletion of abiotic resources are the most relevant PEI categories. Results show generally higher PEs for the acidcatalyzed process, which is particularly pollutant due to the high energy requirements of its methanol recovery unit.

The supercritical methanol process, using propane as cosolvent, is among the three process alternatives the most environmentally favorable, even though methanol and steam usage has an important contribution to its PE\$. Although the supercritical methanol process is highly energy intensive, the downstream operations of methanol recovery and products pufication are much simpler, enabling a decrease in the overall energy consumption by comparison to the other process alternatives.

Steam production is also one of the major contributors to the PEI's of both the alkali and acid-catalyzed processes. Therefore, any effort to reduce the steam requirements of the three process alternatives is seen as a good opportunity for their improvement, in particular to decrease their environmental burdens.

\section{References}

Beer, T., Grant, T., Morgan, G., Lapszewicz, J., Anyon, P., Edwards, J., Nelson, P., Watson, H., Williams, D., 2002. Comparison of Transport Fuels, Stage 2 Study of Life-cycle Emissions Analysis of Alternative Fuels for Heavy Vehicles. CSIRO Atmospheric Research and Australian Greenhouse Gfe.

Boocock, D.G.B., Konar, S.K., Mao, V., Lee, C., Buligan, S., 1998. Fast formation of highpurity methyl esters from vegetable oils. J. Am. Oil Chem. Soc. 75 (9), 1167172.

Bunyakiat, K., Makmee, S., Sawangkeaw, R., Ngamprasertsith, S., 2006. Continuous production of biodiesel via transestefication from vegetable oils in supercritical methanol. Energy Fuels 20, 812817.

Canacki, M., Van Gerpen, J., 1999. Biodiesel production via acid catalysis. Trans. ASAE 42 (5), 1203-1210.

Canacki, M., Van Gerpen, J., 2003. A pilot plant to produce biodiesel from high free fatty acid feedstocks. Trans. ASAE 46 (4), 945954.

Canakci, M., 2007. The potential of restaurant waste lipids as biodiesel feedstocks. Bioresour. Technol. 98 (1), 183-190.

Cao, W., Han, H., Zhang, J., 2005. Preparation of biodiesel from soybean oil using supercritical methanol and co-solvent. Fuel 84, 347351.

CML. Institute of Environmental Sciences, LeidenUniversity. Available dtttp://cml leiden.edu/software/data-cmlia.htm(assessed 29.03.09)

Demisbras, A., 2002. Biodiesel from vegetable oil via transestfixiaiton in supercritical methanol. Energy Convers. Manag. 43, 23492356.

Dorado, M.P., Ballesteros, E., Arnal, J.M., Gómez, J., López, F.J., 2003. Exhaust emissions from a diesel engine fueled with transestefied waste olive oil. Fuel 82,13111315.

Freedman, B., Pryde, E.H., Mounts, T.L., 1984. Variables affecting the yields of fatty esters from transesterfied vegetable oils. J. Am. Oil Chem. Soc. 61, 16381643.

Frischknecht, R., Jungbluth, N., Althaus, H.-J., Doka, G., Heck, T., Hellweg, S., Hischier, R. Nemecek, T., Rebitzer, G., Spielmann, M., 2004. Overview and Methodology. Ecoinvent Report No. 1. Swiss Centre for Life Cycle Inventories, Dübendorf.

Fukuda, H., Kondo, A., Noda, H., 2001. Review: biodiesel fuel production by transesterification of oils. J. Biosci. Bioeng. 92 (5), 405416.

Van Gerpen, J., 2005. Biodiesel processing and production. Fuel Process. Technol. 86 1097-1107.
Guinée, J., 2002. Handbook on Life Cycle Assessment. Operational Guide to the ISO Standard. Kluwer Academic Publishing, Dordrecht, Netherlands.

Haas, M.J., Bloomer, S., Scott, K., 2002. Process for the production of fatty acid alkyl esters, US Patent No. 6,399,800.

Harding, K.G., Dennis, J.S., Blottnitz, H., Harrison, S.T.L., 2007. A life-cycle comparison between inorganic and biological catalysis for the production of biodiesel. J. Clean. Prod. 16, 1368-1378.

Huijbregts, M.A.J., Breedveld, L., Huppes, G., Koning, A., Oers, L., Suh, S., 2003. Normalisationfigures for environmental life-cycle assessment: the Netherlands (1997/1998), Western Europe (1995) and the World (1990 and 1995). J. Clean. Prod. 11, 737-748.

International Standard Organization, 2006. ISO 14040. Environmental management-life cycle assessment-principles and framework. Geneva, Switzerland.

Kasteren, J.M.N., Nisworo, A.P., 2007. A process model to estimate the cost of industrial scale biodiesel production from waste cooking oil by supercritical transesterification. Resour. Conserv. Recycl. 50, 442458.

Kiss, A., Omota, F., Dimian, A., Rothenberg, G., 2006. The heterogeneous advantage: biodiesel by catalytic reactive distillation. Top. Catal. 40, 141150.

Kiwjaroun, C., Tubtimdee, C., Piumsomboon, P., 2009. LCA studies comparing biodiesel synthesized by conventional and supercritical methanol methods. J. Clean. Prod. 17, 143-153.

Knothe, G., Matheaus, A.C., Ryan III, T.W., 2003. Cetane numbers of branched and straight-chain fatty esters determined in an ignition quality tester. Fuel 82, 971-975.

Kusdiana, D., Saka, S., 2001a. Kinetics of transesteficition in rapeseed oil to biodiesel fuels as treated in supercritical methanol. Fuel 80, 693698.

Kusdiana, D., Saka, S., 2001b. Methyl esterifation of free fatty acids of rapeseed oil as treated in supercritical methanol. J. Chem. Eng. Jpn. 34, 38387.

Lepper, H., Friesenhagen, L., 1986. Process for the production of fatty acid esters of short-chain aliphatic alcohols from fats and/or oils containing free fatty acids. US Patent 4608202

Ma, F., Hanna, M.A., 1999. Biodiesel production: a review. Bioresour. Technol. 70, $1-15$.

Ma, F., Clements, L.D., Hana, M.A. 1998. The effects of catalyst, free fatty acids and water on transesterfication of beef tallow. Trans. ASAE 41, 12611264.

Mancosky, D.G., Armstead, D.A., McGurk, T., Hopkins, G., Hudson K., 2007. The use of a controlled cavitation reactor for biodiesel production. AICHE Spring National Meeting, Houston.

Nas, B., Berktay, A., 2007. Energy potential of biodiesel generated from waste cooking oil: an environmental approach. Energy Sources 2, 631.

Phan, A.N., Phan, T.M., 2008. Biodiesel production from waste cooking oils. Fuel 87, 3490-3496.

Sheehan, J., Camobreco, V., Duffield, J., Graboski, M., Shapouri, H., 1998. Life Cycle Inventory of Biodiesel and Petroleum Diesel for Use in an Urban Bus. United States Department of Agriculture and United States Department of Energy (USDA AND U.S. DOE), Colorado.

Srivastava, A., Prasad, R., 2000. Triglyceride based diesel fuels. Renew. Sust. Energy Rev. 4, 111-133.

Utlu, Z., Kocak, M.S., 2008. The effect of biodiesel fuel obtained from waste cooking oil on direct injection diesel engine performance and exhaust emissions. Renew. Energy 33, 1936-1941.

Watanabe, Y., Shimada, Y., Sugihara, A., Tominaga, Y., 2001. Enzymatic conversion of waste edible oil to biodiesel fuel in fixed-bed bioreactor. J. Am. Oil Chem. Soc. 78 (7), 703-707.

Zhang, Y., Dubé, M.A., McLean, D.D., Kates, M., 2003a. Biodiesel production from waste cooking oil: 1. Process design and technological assessment. Bioresour. Technol. 89, 1-16.

Zhang, Y., Dubé, M.A., McLean, D.D., Kates, M., 2003b. Biodiesel production from waste cooking oil: 2 . Economic assessment and sensitivity analysis. Bioresour. Technol. 90, 229-240.

Zheng, S., Kate, M., Dubé, M.A., McLean, D.D., 2006. Acid-catalyzed production of biodiesel from waste frying oil. Biomass Bioenergy 30, 267272. 